\title{
Influence on TSPR's flight envelope by turbocharger
}

\author{
Shi-Chang Liu ${ }^{1, a}$, Jiang Li $^{1}$, Xu-Zhao Yang ${ }^{2, b}$, Yang Liu ${ }^{1}$ and Kai Liu ${ }^{1}$ \\ ${ }^{I}$ Science and Technology on Combustion, Internal Flow and Thermal-structure \\ Laboratory, Northwestern Polytechnical University, Xi'an 710072, China \\ ${ }^{2}$ China Academy of Launch Vehicle Technology No.18 Research Institution, \\ Beijing 100076, China \\ aliushichang1983212@163.com, ${ }^{b} y x z 18 @ 126 . c o m$
}

In this article, the influence on the flight envelope of turbocharged solid propellant ramjet (TSPR) by turbocharger was studied by TSPR's performance prediction program. By those studies, some conclusions were obtained as follows: (1) to increase the compressor's pressure ratio could only expand the flight envelope in low altitude and low Mach number area, while the key factor to limit the maximum flight altitude and flight Mach number was the temperature limit of compressor impeller material; (2) when the temperature limit of compressor impeller raised from $800 \mathrm{~K}$ to $1000 \mathrm{~K}$, TSPR's maximum latitude and Mach number could be raised from $25.5 \mathrm{~km}$ and Ma3.57 to $30.7 \mathrm{~km}$ and Ma 4.1; (3) when the actual turbocharger was introduced, the controlling factors for the maximum latitude and the maximum Mach number would be changed with the raise of the temperature and pressure of the turbocharger's design point, when low pressure and temperature were chosen as the design point the compressor's operating range would be the key factor, and when the high ones were chosen, the temperature limit would be the key factor.

Keywords: Turbocharged Solid Propellant Ramjet; Turbocharger; Flight Envelope; Temperature Limitation; Pressure Limitation.

\section{Introductions}

Modern aircrafts ask for series of new requirements, such as high speed, wide envelope, full range power control, and so on, which make the traditional powers inadequate. So, lots of combined engines emerged. Among those engines, 
air turbocharged ramjet (ATR) attracted common attention greatly for its high specific impulse, high specific thrust, and long range. Its working process could be described as follow: the gas generator produced fuel-rich gas to drive turbine to generate power, which made the compressor to pressurize air; turbo-driving gas and pressurized air flew into afterburner and burnt there to produce thrust. The turbo-driving gas for ATR would be used for both turbine driving and afterburning, which brought propellant selection series of difficulties. Because of that, with the rising of turbine expansion ratio, the specific impulse and specific thrust of ATR would be changed in different trends, for which some compromise had to be made between specific impulse and specific thrust in ATR design. Therefore, a new concept was proposed. The gas, used for both turbine driving and afterburning in ATR, was divided into two kinds of gas, one of which was used for turbine driving and the other was used for afterburning. Then the turbo-driving gas could be chosen as some clean and low temperature gas to ensure turbine's safety, and the afterburning gas could be chosen as some high enthalpy gas to improve the whole engine's energy feature, by doing these, the working characteristics' trends were changed, that, with the increasing of turbine expansion ratio, the specific impulse and the specific thrust of ATR would be improved at the same time. The engine was named as turbocharged solid propellant ramjet (TSPR).

Because of the use of turbomachinary, those engines had the advantages at long range flight, acceleration, and the capability of take-off in Mach 0 on the ground. [1] Especially, under the regulation of turbomachinary, the working range was enlarged greatly, so that the engine's task type was expanded, for which the engine could be used for multi-task operation. $[2,3,4]$ Therefore a series of studies on the engine were carried out. The affects on the ATR performance by turbocharger were summarized by JA Bossard et, and, on that basis, the selection and design methods for ATR turbocharger system were summarized also. [5] And then, Kirk Le Christensen described his modeling concept for the ATR turbocharger system in the paper, and the main influences on ATR overall performance by turbocharger were discussed by the model [6]. In view of the limitations of ATR cycle, the concept of TSPR was proposed [7], then a lot of studies about TSPR were carried out by Sa Yang, Moran, Yang Yun, such as the circulation of turbocharger system in TSPR, [7] the law of influence on TSPR performance by turbocharger system, [8] modeling for TSPR turbocharger system, [9] the selection and design method for TSPR turbocharger system, $[8,9]$ and so on.

Based on those researches above, the paper discussed the influences on TSPR engine working range by turbocharger with TSPR's performance indicating program, under the limitations of TSPR working constrains. 


\section{Physical Model and Constraints}

\subsection{Physical model}

TSPR includes six main components: inlet, turbocharger, turbo-driving gas generator, fuel-rich gas generator, afterburner and nozzle, which were shown in Fig.1.

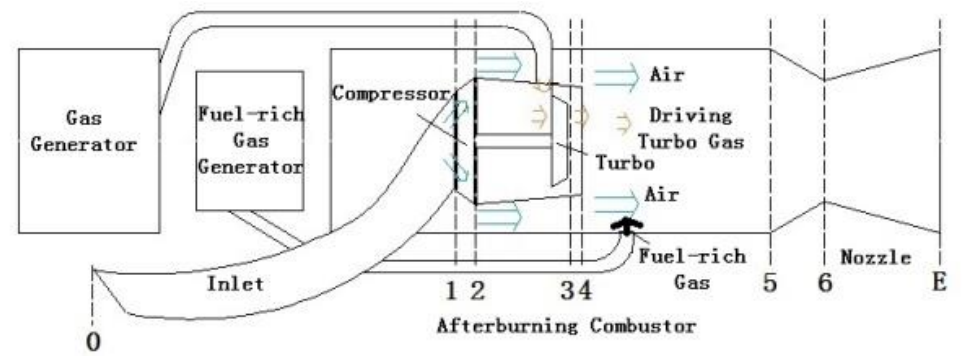

Fig.1. Schematic diagram of TSPR

The TSPR could be divided into eight computing section according to the component's operating parameters, there were: 0 , inlet entrance section, calculated by operating state; 1 , inlet exit section and the compressor entrance section, calculated by inlet model; 2, compressor exit section, calculated by compressor model; 3, turbine entrance section, calculated by turbine nozzle's model with turbo-driving gas's parameters; 4, turbine exit section, calculated by the turbine model; 5, afterburner section, calculated by CEA with the parameters of turbo-driving gas, fuel-rich gas and air; 6, nozzle entrance section, calculated by CEA with the calculation results of 5 section; e, nozzle exit section, calculated by nozzle model. The model could indicate the design and off-design points.

In the calculation, turbine and compressor should abide by the match law, that the speed, power and the pressure on the exit should keep balance with each other. The $\mathrm{C}-\mathrm{H}$ solid propellant was chosen for turbo-driving gas generator, whose production was clean and the complete combustion energy was 10-15 MJ / Kg. And the fuel-rich propellant's complete combustion energy was $30-40 \mathrm{MJ} /$ $\mathrm{Kg}$.

\subsection{Basic assumptions and constrains}

In the calculation, the following assumptions were taken [9]:

(1) TSPR was operated in steady, without friction and heat insulated state, ignoring the energy loss in the nozzle;

(2) The influence on pressure of the afterburner by the turbo-driving gas 
exiting from turbine and the fuel-rich gas was ignored, and the pressure in the afterburner was equal to the pressure of pressurized air exiting form turbocharger;

(3) During the operation period, turbo-driving gas and fuel-rich gas's parameters does not change, and the turbo-driving gas's temperature was not higher than $1450 \mathrm{~K}$.

According to the ignition limit of Boron particles, the pressure in the afterburner should be no less than $0.2 \mathrm{MPa}$. The temperature of compressor impeller and should be limited according to the material. The impeller was usually made by high-strength aluminum alloy, whose temperature limitation was $800 \mathrm{~K}$, or titanium alloy, whose temperature limitation was $1000 \mathrm{~K}$. Then the constraints could be summarized as follows:

(1) $\mathrm{P}_{\text {com }}>=0.2 \mathrm{MPa}$;

(2) For aluminum alloy, $\mathrm{T}_{\text {comp }}<=800 \mathrm{~K}$; for titanium alloy $\mathrm{T}_{\text {comp }}<=1000 \mathrm{~K}$;

(3) $\mathrm{T}_{\text {inlet }}<=1000 \mathrm{~K}$ 。

The subscript com represented the afterburner, comp represented the compressor, inlet represented the inlet; $\mathrm{P}$ referred to the pressure, $\mathrm{T}$ referred to the temperature.

\section{Calculation and Analysis}

\subsection{TSPR flight envelope for ideal turbocharger}

According to the constraints and model above, the TSPR flight envelope was calculated in different impeller materials and boost capacities.

When the impeller material was aluminum, the maximum pressure ratio was 3 , the compressor efficiency was assumed to be 0.8 , and the compressor's flow rate range was ignored, the flight envelopes were shown in Fig.2. The minimum pressure ratio was defined as the minimum pressure ratio to meet the constraints; the minimum temperature was defined as the lowest temperature the pressurized air could reach. It could be found that the boundary was divided into three sections, the left line was low speed boundary, which was constrained by the minimum pressure; the top line was the maximum latitude boundary and the right line was the high speed boundary, which were constrained by the material's temperature limitation.

If the impeller material and the turbocharger's efficiency were kept the same, while the maximum pressure ratio was improved to 6 , the flight envelopes could be calculated and shown in Fig.3. It could be found that the raise of the maximum pressure ratio could not expand the maximum altitude and the maximum flight speed boundary. The maximum altitude was still $25.5 \mathrm{Km}$, and the maximum flight Mach number was still 3.57. 
If the impeller material was changed to titanium, while the maximum pressure ratio and efficiency were kept the same, the envelope could be calculated and shown in Fig.4. It could be found that the titanium alloy material expanded the flight envelope significantly, that the maximum altitude boundary could be expanded to $30.7 \mathrm{Km}$, and the maximum flight Mach number could be expanded to 4.1. Compared with the envelopes in Fig.2, it could be found that the maximum altitude and Mach number were limited by the maximum permissible material temperature.

Based on the calculation and analysis above, when TSPR worked under the ideal turbocharger without flow rate limitation, the flight envelope boundary could be divided into three parts, which were the minimum speed boundary, the maximum latitude boundary and the maximum speed boundary. The minimum speed boundary was controlled by the maximum turbocharger pressure ratio; the maximum altitude boundary and the maximum were controlled by the maximum temperature of the impeller material. When the maximum pressure ratio changed from 3 to 6 , the minimum speed boundary could be expanded $17.5 \%$. When maximum temperature of impeller material was improved from $800 \mathrm{~K}$ to $1000 \mathrm{~K}$, the maximum altitude boundary could be expanded $20.4 \%$, and the maximum speed boundary could be expanded $14 \%$.

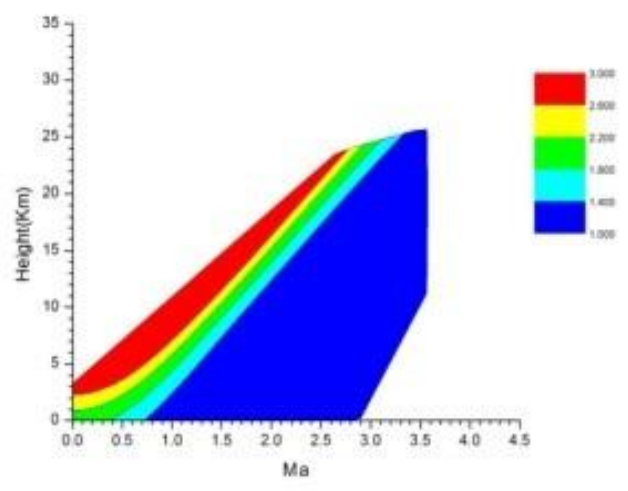

(a) distribution of min pressure ratio 


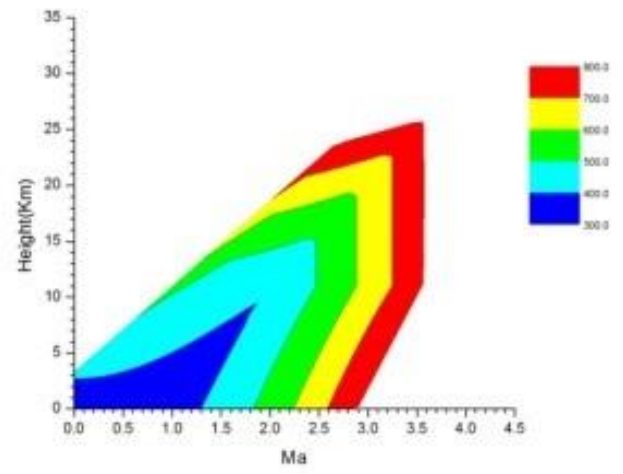

(b) distribution of min temperature

Fig.2. flight envelopes in max pressure ratio 3 with aluminum alloy

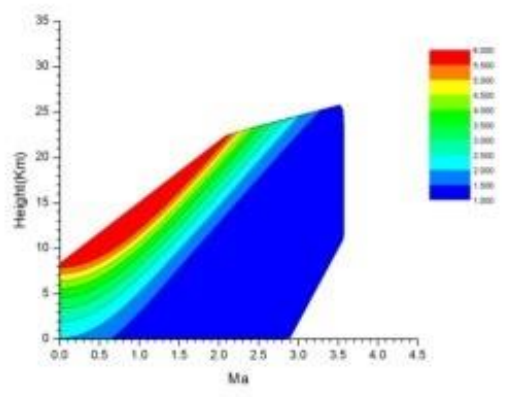

(a) distribution of min pressure ratio

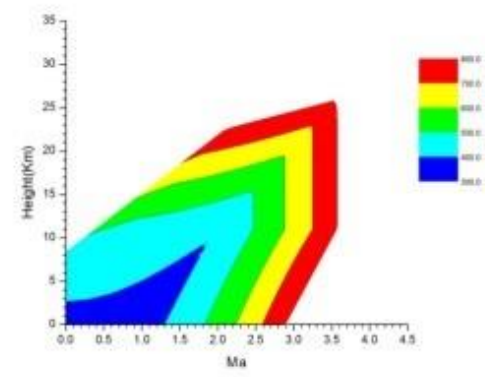

(b) distribution of min temperature

Fig.3. flight envelopes in max pressure ratio 6 with aluminum alloy 


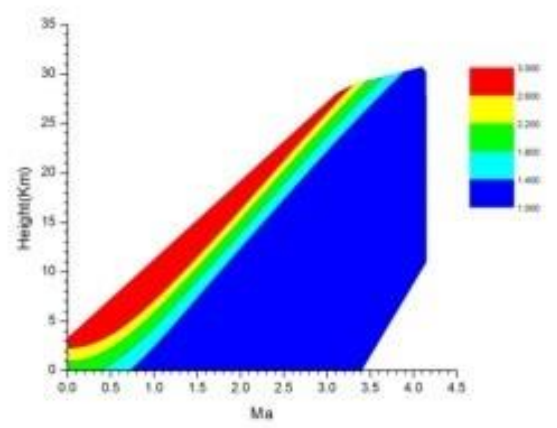

(a) distribution of min pressure ratio

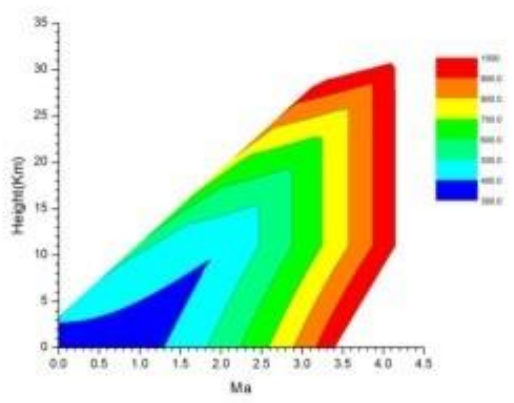

(b) distribution of min temperature

Fig.4. flight envelopes in max pressure ratio 3 with titanium alloy

\subsection{TSPR flight envelope for an actual turbocharger}

The calculation and analysis above were operated with the ideal turbocharger without the flow rate consideration. But each turbocharger had its flow rate limitation. So an actual turbocharger was designed to discuss the influences on TSPR flight envelope by the turbocharger's operating range. The actual turbocharger's design point was normal pressure and temperature, and the pressure ratio was 3 and the flow rate was $1.5 \mathrm{~kg} / \mathrm{s}$, whose pressure ratio and efficiency maps were shown in Fig.5.

With the compressor characteristic maps in Fig.5, TSPR's envelopes were calculated and shown in Fig.6, which were distributions of pressure (pa), temperature $(\mathrm{K})$, conversion flux $(\mathrm{kg} / \mathrm{s})$ and conversion rotation speed $(1 / \mathrm{min})$. The pressure was defined as the pressure in the afterburner, which was constrained by the minimum pressure limitation. The temperature was defined as the total temperature of the pressurized air, which was constrained by the 
maximum temperature limitation according to the impeller material. The left boundary of the envelope was still controlled by the minimum pressure limitation compared with the envelope with ideal turbocharger, but the rake ratio of the left boundary was smaller than the ideal ones, which was caused by the surge margin of the actual turbocharger. The maximum latitude boundary and the maximum speed boundary were reduced, and they were not controlled by the temperature limitation as the envelope with an ideal turbocharger. According to the distributions of conversion flux and speed and the turbocharger's characteristic maps, it could be found that the top boundary and the right boundary were controlled by the operating range of the turbocharger. If the pressure and temperature in the same pressure ratio and flow rate of turbocharger's design point was raised higher and higher, the temperature on the maximum latitude boundary and the maximum speed boundary would rise until reach to the temperature limitation of the impeller material.

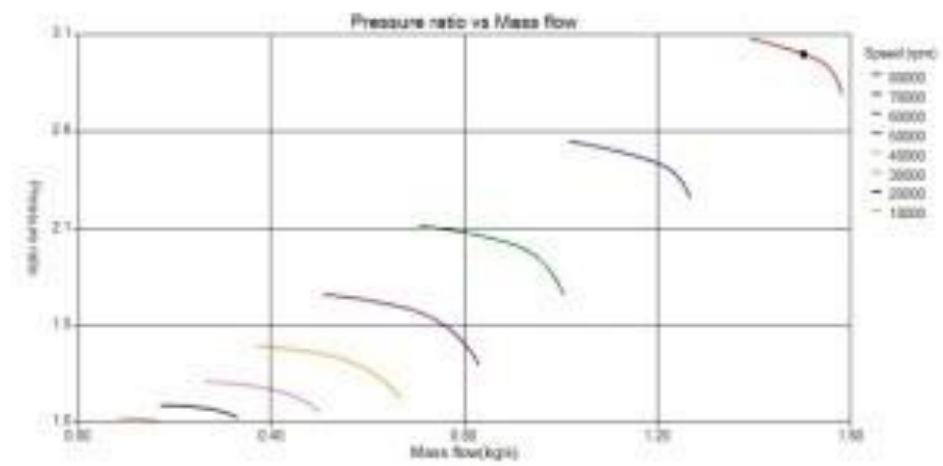

(a) pressure ratio vs. flux

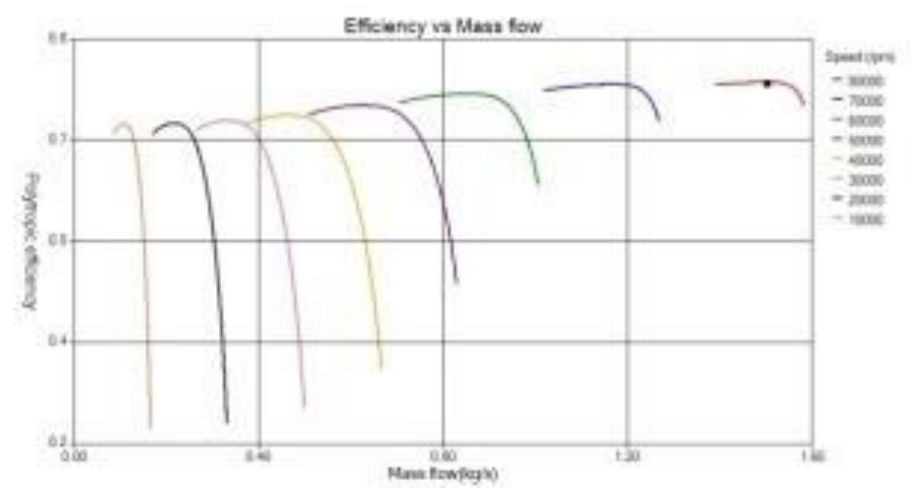

(b) efficiency vs. flux

Fig.5. compressor characteristic map 


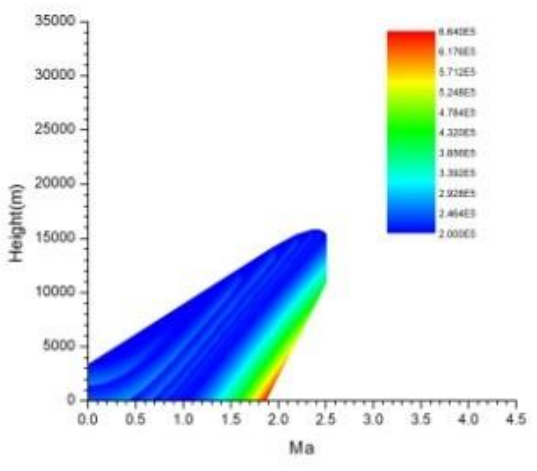

(a) distribution of pressure

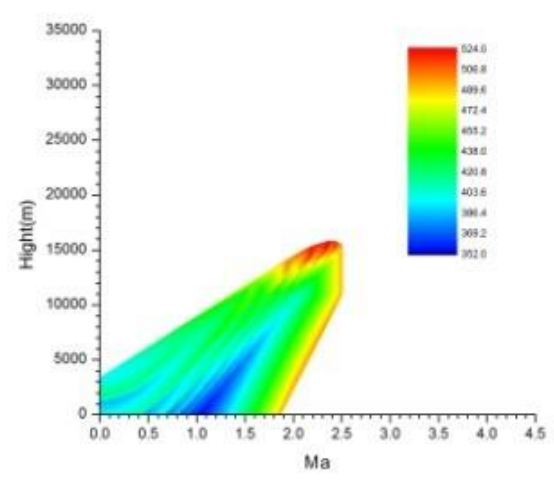

(b) distribution of temperature

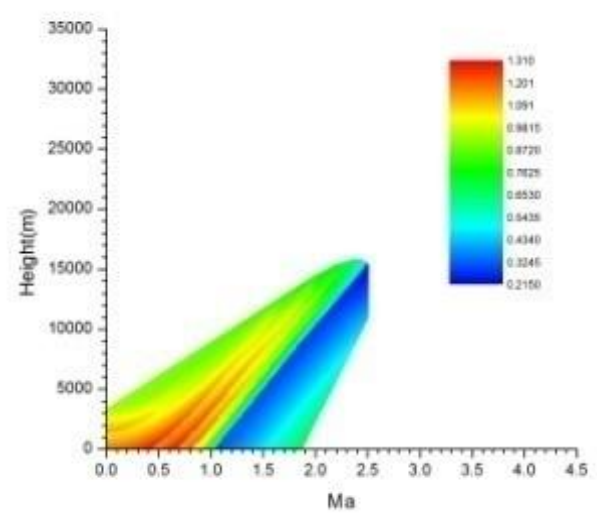

(c) distribution of conversion flux 


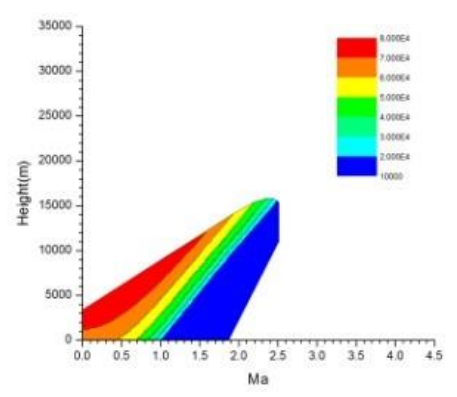

(d)distribution of conversion rotation speed

Fig.6 flight envelope in max pressure ratio 3

Then it could be concluded that, when an actual turbocharger was introduced, the envelope of TSPR could also be divided into three parts. The low speed boundary was controlled by the pressure limitation. When the turbocharger's design point was focus on the low temperature and pressure, the maximum latitude boundary and the maximum speed boundary were controlled by the turbocharger's operating range; when the turbocharger's design point was focus on the high temperature and pressure, the maximum latitude boundary and the maximum speed boundary were controlled by the temperature limitation of the impeller material.

\section{Conclusions}

The influence on the TSPR's flight envelope by the turbocharger was discussed by TSPR model and operating constraints, from which three main conclusions could be obtained:

(1) When an ideal turbocharger was introduced into calculation and the impeller material was chosen as aluminum. When the turbocharger's maximum pressure ratio was changed from 3 to 6 , without cooling device, the minimum speed boundary could be expanded by $17.5 \%$. However, the maximum latitude of the TSPR was $25.5 \mathrm{~km}$, and the maximum Mach number was 3.57 , which would not be changed with the change of turbocharger's maximum pressure ratio.

(2) When the ideal turbocharger's impeller material was changed to titanium alloy, and other situations were kept still. The maximum flight height and the maximum Mach number could be extended to $30.7 \mathrm{~km}$ and Mach 4.1 , which meant that the maximum altitude boundary could be expanded by $20.4 \%$, and the maximum speed boundary could be expanded by $14 \%$ compared with the impeller in aluminum. 
(3) When an actual turbocharger was introduced into TSPR envelope calculation, the minimum speed boundary was still controlled by the pressure limitation, but the key factors for the maximum latitude boundary and the maximum speed boundary would be changed with the raise of the temperature and pressure of the turbocharger's design point. When the temperature and pressure was low, those two boundaries were controlled by the turbocharger's operating range. When they became high, those two boundaries were controlled by the temperature limitation of the impeller material.

\section{References}

[1]. M. Thomas, et al., Addressing emerging tactical missile propulsion challenges with the solid propellant air-turbo-rocket $[\mathrm{J}]$, \& Proceedings AIAA, 2000.

[2]. F. Haglind, et al., Design of a Solid Propellant Air Turbo Rocket for a Tactical Air-Launched Missile, GT2007-27826.

[3]. M. Thomas, et al., Air-Turbo-Ramjet Propulsion for Tactical Missiles [J], \&Proceedings AIAA, 1994.

[4]. M. Thomas, Monorotor Turbomachinery for Air Turbo Ramjet Propulsion [J], \&Proceedings AIAA, 1995.

[5]. J. A. Bossard, et al., Customized turbomachinery for solid-propellant air turbo rockets[J], \& Proceedings AIAA, 1997.

[6]. Kirk Le Christensen,Vehicle Performance Optimization Utilizing the Air Turbo-Ramjet Propulsion System:Methodology Development and Applications,A Dissertation of Doctor of Philosophy in Aerospace Engineering,United States,UMI,1997.

[7]. Mo Ran, Modeling and Performance Analysis of Turbocharged Solid Propellant Ramjet [D], Xi'an: Northwestern Polytechnical University, 2011.

[8]. Yang Yun, Design and Performance Simulation of Compressor-Turbine in Turbocharged Solid Propellant Ramjet [D], Xi'an: Northwestern Polytechnical University, 2013.

[9]. Yang Sa, Investigation on Turbocharged Solid Propellant Ramjet Technology [D], Xi'an: Northwestern Polytechnical University, 2013. 